\title{
MANHAJ TAFSIR DALAM MEMAHAMI AYAT-AYAT KISAH DALAM AL QURAN
}

\author{
Vmaiyatus Syarifah \\ Fakultas Saintek, UIN Maulana Malik Ibrahim Malang. Jalan Gajayana No. \\ 50 Malang. email: Umayyah.syarifah@gmail.com
}

\begin{abstract}
The narrative verses in the Holy Quran mainly function to lead the morality (akhlaq) of the society. Islam has guiding principles for interpreting such verses so that Moslems can gain objective comprehension upon them. One of the foremost principles is to view the narratives as mysterious events and only Allah SWT knows the sequential facts-say, the real chronologies- of the stories. Besides, Moslems should not rely on the validity of the narratives on ahl al kitab's explanation. It is, finally, imperative that any stories be confirmed and rechecked across reliable sources, such as al Quran, hadith, and ulama's trustworthy interpretation (tafsir). As the interpretation of narrative verses spread very fast orally or in written, it might be unexpectedly interfered by some Israiliyat stories. This paper provides some insights to respond the subsistence of Israiliyats. First, the validity of the Israiliyats should always be questioned except when al Quran and Hadith have provided evident points of justification. Second, the Israiliyats whose content is appropriate with the teachings of al Quran and hadith can enrich our religious perspectives. Third, the Israiliyats whose content contradicts Islamic values (syari'ah) should be disregarded and thrown away. Last but not least, fourth, that it is prohibited to tell false stories.
\end{abstract}

Kisah al Quran merupakan salah satu media penyampaian pesan-pesan moral dalam rangka pembentukan umat yang memiliki akhlak mulia. Al Quran mempunyai manhaj dalam mencermati kisah-kisah al Quran agar penilaian kita menjadi objektif dan benar, di antaranya adalah bahwa kisah dalam al Quran termasuk dalam kategori "berita-berita gaib" dan hanya Allah SWT yang benar-benar mengetahui kronologi sebenarnya dari kisah-kisah tersebut. Selain itu, kaum Muslim tidak menyandarkan validitas kisah-kisah tersebut pada penjelasan para ahli kitab. Selanjutnya, konfirmasi ulang terhadap setiap 
berita, fenomena dan dinamika sebelum memberikan penilaian terhadap berita merupakan konsep dari al Quran sendiri. Konfirmasi terhadap kisah-kisah ini hendaknya dilakukan dengan sumber-sumber yang dapat dipercaya, seperti al Quran, hadits, dan tafsir. Sejalan dengan begitu cepatnya penyebaran dari interpretasi kisah-kisah ini secara lisan dan tulisan, maka terdapat banyak kemungkinan tercampurnya kisah-kisah tersebut dengan kisah-kisah Israiliyat. Tulisan ini menyajikan beberapa pandangan untuk menyikapi keberadaan kisahkisah Israiliyat tersebut. Pertama, kita tidak bisa memastikan kebenaran apapun dari Israiliyat kecuali al Quran dan hadits memastikannya. Kedua, riwayat Israiliyat yang benar menurut sumber kita maka statusnya menjadi wawasan pengetahuan kita. Ketiga, Israiliyat yang menyalahi dan mengingkari syariat kita maka tidak boleh meriwayatkannya, kecuali hanya untuk menjelaskan kekeliruannya. Keempat, Riwayat yang palsu, kita tidak diperbolehkan untuk meriwayatkannya.

Key words: interpretation method (manhaj tafsir), narrative verses, Israiliyat

\section{Pendahuluan}

"Sesungguhnya ini adalah kisah yang benar, dan tak ada Tuhan (yang berhak disembah) selain Allah; dan sesungguhnya Allah, Dia-lah Yang Maha Perkasa lagi Maha Bijaksana”.

Al Quran mempunyai dua fungsi utama, yaitu sebagai sumber ajaran, dan bukti kebenaran kerasulan Muhammad SAW. Sebagai sumber ajaran, al Quran memberikan berbagai norma keagamaan sebagai petunjuk bagi kehidupan umat manusia untuk mencapai kebahagiaan di dunia dan di akhirat (syariah).

Di samping sebagai sumber ajaran, al Quran juga disampaikan Allah SWT untuk menjadi bukti kebenaran kerasulan Muhammad SAW, terutama bagi mereka yang menentang dakwah-dakwahnya. Bukti-bukti kebenaran tersebut dalam kajian Ulum al Quran disebut mukjizat.

Di antara mukjizat al Quran adalah penyampaian ajaran-ajarannya yang disampaikan secara variatif serta dimodifikasi dalam bentuk deskripsi kisah-kisah. Kisah al Quran merupakan salah satu media penyampaian pesanpesan moral dalam rangka pembentukan umat yang memiliki akhlak mulia sebagaimana yang diperjuangkaan oleh Nabi Muhammad SAW.

Oleh karena itu, sebagai muslim yang kritis, kita seharusnya mempunyai konsep yang benar dalam mencermati ayat-ayat kisah sehingga dapat merenungkan setiap ayat mengandung pelajaran dari kisah-kisah orang terdahulu agar tidak jatuh dalam kesesatan «mitos-mitos», dongeng-dongeng atau juga legenda 
bohong yang mayoritas dinukil dari sumber-sumber Israiliyat, juga hal hal yang menghalangi kita dalam mengambil pelajaran, petunjuk dan hikmah dari esensi suatu kisah.

\section{Kisah dalam al Quran}

Kata kisah berasal dari bahasa arab jama'nya qishash yang berarti cerita (Munawwir, 1997: 1.126), al Qashsh adalah masdar dari kata kerja Qashasha yang berarti mengisahkan. Jadi kisah adalah cerita dari suatu kejadian yang sudah diketahui sebelumnya (Khalafullah, 2002: 100). Kisah bermakna "hikayat (dalam bentuk) prosa yang panjang”, sedangkan menurut Manna Khalil al Qattan bermakna mencari atau mengikuti jejak (Ibrahim, 1969: 140).

Imam ar Raghib al Ishfahani mengatakan dalam Mufradat fi gharib al Quran menyatakan "al Qashshu" berarti mengikuti jejak. Dikatakan, qashashtu atsarahu saya mengikuti jejaknya (al Khalidy, 4523 H: 21). Kisah, Naba' dan Khabar merupakan sinonim dengan makna "mengikuti kejadian lalu", dengan pembedaan secara umum bahwa Naba' hanya untuk kejadian yang berjauhan, sedangkan khabar untuk kejadian dalam waktu yang berdekatan. Kata al Qashash bisa bermakna mengikuti seperti tertulis dalam al Quran: Musa berkata: «Itulah (tempat) yang kita cari». Lalu keduanya kembali, mengikuti jejak mereka semula (QS al Kahfi: 64).

Maksudnya kembali lagi mengikuti jejak dari mana keduanya datang. Qashash juga bermakna memindahkan cerita, cerita yang dikisahkan dan khabar yang berturut-turut (Abdurrahim, 1995: 159) Allah berfirman: "Kami menceritakan kepadamu kisah yang paling baik" (QS Yusuf: 3).

Dari segi istilah, kisah berarti berita-berita mengenai suatu permasalahan dalam masa-masa yang saling berturut-turut. Sedangkan Qashash al Quran adalah pemberitaan mengenai keadaan umat yang telah lalu, nubuwat yang terdahulu dan peristiwa-peristiwa yang terjadi (al Qaththan, 1973: 57). M. Khalafullah membagi definisi kisah pada pendekatan dua arah, pertama, pendekatan etimologi seperti yang bisa kita baca di atas, kedua, pendekatan religius, yaitu mengaitkannya dengan maksud dan tujuan kisah-kisah al Quran itu sendiri. Kisah tidak hanya sekedar menceritakan sebuah berita namun kisah adalah sebuah karya sastra dalam kapasitasnya sebagai hasil imajinasi seorang pengisah atas kejadian tertentu yang dialami oleh seorang tokoh tak dikenal, ataupun sebaliknya. Inilah definisi kisah ketika memasuki ruang lingkup kesusasteraan (Khalafullah, 2002: 101).

Jadi kisah al Quran adalah pemberitaan mengenai nabi, umat-umat dan 
peristiwa terdahulu, dan juga kejadian akan datang yang mengandung nilai dan juga hikmah bagi Nabi Muhammad SAW dan umatnya.

\section{Macam-Macam Kisah}

Kisah-kisah dalam al Quran terbagi dalam dua bentuk:

1. Kisah para Nabi meliputi dakwah pada kaumnya, mukjizat yang menyertainya, kaum yang menyimpang, perjalanan dan perkembangan dakwah serta hal hal yang terjadi atas orang-orang mukmin dan kafir. Seperti kisah Nuh, Ibrahim, Musa, Muhammad dan nabi-nabi yang lain. Dan (ingatlah kisah) Ismail, Idris dan Dzulkifli. Semua mereka termasuk orang-orang yang sabar (QS al Anbiyaa: 85).

2. Kisah-kisah yang berhubungan dengan kejadian masa lampau, pribadipribadi yang tidak ditetapkan kenabiannya, seperti kisah Dzulqarnain, Qarun, Ashabul Kahfi dan lain-lain. "Atau kamu mengira bahwa orang-orang yang mendiami gua dan (yang mempunyai) raqim itu, mereka termasuk tandatanda kekuasaan Kami yang mengherankan" (QS al Kahf: 9).

M. Abdurrahim dalam mu'jizat wa ajaib, menambahkan satu macam kisah mengenai kejadian-kejadian yang terjadi pada masa Nabi Muhammad SAW masih hidup seperti kisah perang badar, uhud, Ahzab dan lain-lain. Berbeda dengan Khalafullah yang memberikan beberapa model kisah al Quran sesuai dengan model yang berlaku dalam dunia sastra: model sejarah, yakni kisah yang menceritakan sejarah tertentu seperti cerita nabi dan rasul. Model perumpamaan, kisah-kisah yang menurut orang terdahulu, kejadiannya dimaksudkan untuk menerangkan dan menjelaskan suatu hal atau nilai-nilai. Peristiwa ini tidak perlu benar-benar terjadi dan bisa hanya cerita fiktif. Model legenda, kisah yang diambil dari mitos-mitos yang dikenal dan berlaku dalam sebuah komunitas sosial (Khalafullah, 2002: 101). Umumnya, tujuan kisah model seperti ini adalah untuk memperkuat satu tujuan pemikiran.

Al Quran mempunyai manhaj dalam mencermati kisah-kisah al Quran agar penilaian kita menjadi objektif dan benar, di antaranya:

1. Kisah dalam al Quran adalah hal gaib. Kita harus meyakini bahwa kisah dalam al Quran termasuk dalam kategori "berita-berita gaib”, karena hal gaib dalam Islam ada tiga macam, yaitu:

a. Gaib masa lampau, yaitu kisah orang terdahulu, seperti kisah Adam as dengan Iblis, kisah Nuh, kaum Aad, Tsamud dan lain-lain.

b. Gaib masa kini (sekarang), seperti "alam-alam gaib” yang ada sekarang 
yang memiliki entitas, kehidupan, dan eksistensinya, tetapi kita tidak bisa melihatnya, seperti kisah alam malaikat, jin dan setan.

c. Gaib masa depan, seperti ayat-ayat dan Hadits-hadits sahih yang berbicara tentang hal hal dan peristiwa-peristiwa yang akan terjadi di masa depan, seperti tanda-tanda hari kiamat dan babak-babak peristiwa kiamat (al Khalidy, 4523 H: 32).

Jika kita amati dari beberapa kisah nabi-nabi terdahulu, al Quran mengomentari uraian peristiwa-peristiwa tersebut sebagai berita gaib yang Allah wahyukan kepada Nabi Muhammad SAW, seperti dalam surat Hud, setelah al Quran menceritakan kisah Nabi Nuh as.

"Itu adalah di antara berita-berita penting tentang yang ghaib yang Kami wahyukan kepadamu (Muhammad); tidak pernah kamu mengetahuinya dan tidak (pula) kaummu sebelum ini. Maka bersabarlah; sesungguhnya kesudahan yang baik adalah bagi orang-orang yang bertakwa" (QS Huud: 49).

Dalam penutup kisah Nabi Yusuf as, al Quran juga menyebutkan akan kegaiban kisah tersebut:

"Demikian itu (adalah) di antara berita-berita yang ghaib yang Kami wahyukan kepadamu (Muhammad); padahal kamu tidak berada pada sisi mereka, ketika mereka memutuskan rencananya (untuk memasukkan Yusuf ke dalam sumur) dan mereka sedang mengatur tipu daya" (QS Yusuf, 12:102).

Dengan pemahaman bahwa kisah merupakan hal gaib, kita tidak bisa dengan mudahnya mengklaim waktu kejadian suatu peristiwa baik yang sudah terjadi ataupun belum terjadi kecuali al Quran dan hadits menjelaskannya.

2. Kita tidak hadir di tengah mereka

Mengingat kisah orang-orang terdahulu adalah termasuk hal gaib masa lampau maka hanya Allah SWT yang mengetahuinya, hanya Dia-lah yang mengetahui peristiwa dan perinciannya. Allah berfirman:

"Dan kepunyaan Allah-lah apa yang ghaib di langit dan di bumi dan kepada-Nya-lah dikembalikan urusan-urusan semuanya, maka sembahlah Dia, dan bertawakkallah kepada-Nya. Dan sekali-kali Tuhanmu tidak lalai dari apa yang kamu kerjakan." (QS Hud: 123).

Rasulullah telah menyatakan secara terang-terangan bahwa beliau tidak mengetahui hal gaib-kecuali melalui apa yang diajarkan Allah kepadanya dan Allah mengajarkan beliau untuk menceritakan kepada umat manusia. 
"Katakanlah: "Aku tidak berkuasa menarik kemanfa' atan bagi diriku dan tidak (pula) menolak kemudharatan kecuali yang dikehendaki Allah. Dan sekiranya aku mengetahui yang ghaib, tentulah aku membuat kebajikan sebanyak-banyaknya dan aku tidak akan ditimpa kemudharatan. Aku tidak lain hanyalah pemberi peringatan, dan pembawa berita gembira bagi orangorang yang beriman" (QS al Naml: 65).

Ayat di atas mengindikasikan bahwasanya firman Allah tersebut menafikan pengetahuan Rasulullah SAW tentang hal tersebut andaikan beliau bukanlah Nabi. Tujuan peniadaan ini adalah bentuk penetapan dan pengukuhan wahyu dan risalah Tuhan, dan penjelasan bahwa kisah-kisah dari Allah dan Muhammad SAW. Kalau dia bukan rasul niscaya beliau tidak akan mengetahuinya.

\section{Allah SWT Maha Tahu atas kisah}

Al Quran menceritakan kepada kita bahwa sebagian peristiwa dari kisah orang-orang terdahulu, para pelaku, dan nama-nama mereka tidak ada yang mengetahui kecuali Allah SWT. Sesuai firman-Nya: "Belumkah sampai kepadamu berita orang-orang sebelum kamu (yaitu) kaum Nuh, 'Ad, Tsamud dan orang-orang sesudah mereka. Tidak ada yang mengetahui mereka selain Allah" (QS Ibrahim: 9).

Kita mengambil isyarat visi Qurani yang tajam dalam mengamati sejarah, mengkaji dan berinteraksi dengannya. Sejarah manusia adalah kehidupan umat manusia sendiri, yang ditulis, diabstraksikan dan dituturkan. Sejarah baru ditulis di masa berikutnya, yang hanya sedikit menangkap; dari peristiwa dan rincian kronologis serta historis dari sejarah itu. Oleh karena itu, kita tidak bisa membuat atau juga mengkonsumsi penjelasan-penjelasan kecuali yang Allah SWT (al Quran) firmankan maupun yang Nabi Muhammad SAW (Sunnah) sabdakan.

\section{Jangan menyandarkan kisah-kisah pada ahli kitab}

Al Quran secara terang-terangan melarang kita menanyakan kepada ahli kitab tentang kisah-kisah orang terdahulu, rincian serta nama pelaku, tempat maupun peristiwanya. Hal ini disebutkan di sela-sela penyebutan kisah Ashabul Kahfi dan perselisihan di antara orang-orang terdahulu tentang jumlah pemuda tersebut.

"Nanti (ada orang yang akan) mengatakan (jumlah mereka) adalah tiga orang yang keempat adalah anjingnya, dan (yang lain) mengatakan: "Jumlah 
mereka) adalah lima orang yang keenam adalah anjingnya”, sebagai terkaan terhadap barang yang gaib; dan (yang lain lagi) mengatakan: "(Jumlah mereka) tujuh orang, yang kedelapan adalah anjingnya". Katakanlah: "Tuhanku lebih mengetahui jumlah mereka; tidak ada orang yang mengetahui (bilangan) mereka kecuali sedikit”. Karena itu janganlah kamu (Muhammad) bertengkar tentang hal mereka, kecuali pertengkaran lahir saja dan jangan kamu menanyakan tentang mereka (pemuda-pemuda itu) kepada seorangpun di antara mereka" (QS al Kahfi: 22).

Larangan pada ayat ini ditujukan kepada setiap muslim, sebagaimana ditujukan pada Rasulullah SAW karena (perintah maupun larangan) yang ditujukan kepada Nabi Muhammad juga ditujukan kepada umatnya.

Ibnu Abbas berkata, "maka janganlah kamu bertengkar tentang hal mereka kecuali pertengkaran lahir semata, "artinya, cukuplah bagimu apa yang telah Aku (Allah) kisahkan kepadamu, maka janganlah kamu bertengkar lagi tentang mereka.” Ayat di atas merupakan bentuk pelarangan konfirmasi cerita Ashabul kahfi kepada seorang pun dari (ahli kitab), karena mereka tidak memiliki pengetahuan tentang hal itu, kecuali apa yang mereka katakan dari karangan mereka sendiri, tanpa berdasarkan keterangan yang benar (tafsir Ibnu Katsir, 3: 870).

\section{Konfirmasi terhadap setiap berita}

Allah berfirman:

"Dan janganlah kamu mengikuti apa yang kamu tidak mempunyai pengetahuan tentangnya. Sesungguhnya pendengaran, penglihatan dan hati, semuanya itu akan diminta pertanggungan jawabnya” (QS al Isra: 36).

Sayyid Qutb mengatakan bahwa ayat ini memaparkan tentang konsep yang komprehensif bagi akal dan hati yang mencakup metodologi ilmiah yang dikenal oleh umat mannusia, serta menambahkan padanya konsistensi jiwa dan perasaan yang selalu taqarub kepada Allah (al Khalidy: 38). Konfirmasi ulang terhadap setiap berita, fenomena dan dinamika sebelum memberikan penilaian terhadap berita merupakan konsep dari al Quran sendiri. Ketika kita konsisten dengan konsep ini maka tidak akan ada ruang ilusi bagi mitosmitos dalam dunia akidah, prasangka dan praduga dalam hukum, peradilan dan interaksi social, tidak akan ada hipotesis dangkal dan asumsi ilusif dalam riset, ekperimen maupun sains.

\section{Periksa ulang berita-berita yang datang}

Allah berfirman:

"Hai orang-orang yang beriman, jika datang kepadamu orang fasik membawa 
suatu berita, maka periksalah dengan teliti, agar kamu tidak menimpakan suatu musibah kepada suatu kaum tanpa mengetahui keadaannya yang menyebabkan kamu menyesal atas perbuatanmu itu" (QS al Hujarat: 6)

Ayat ini memberikan kepada kita sebuah konsep Qurani dalam memeriksa, menyaring dan mengecek berita jika sumber-sumbernya adalah orang-orang fasik. Ayat ini menjelaskan bahwasanya orang fasik tidak dapat dipercaya. Kebohongan, distori, dan manipulasi informasi senantiasa memasuki berita dan informasi yang mereka sampaikan. Oleh karena itu, sudah semestinya berita yang datang dari riwayat mereka diletakkan pada parameter, penyaringan dan pemeriksaan yang tepat.

\section{Hukum Meriwayatkan Kisah Israiliyat}

Sebagaimana pemalsuan yang telah tersebar di dalam kitab-kitab Tafsir, begitupula dengan Israiliyyat. Ada yang menganggap bahwa Israiliyyat telah muncul sejak zaman para Shahabat. Sebagian Shahabat apabila dihadapkan pada sebuah kisah dari kisah-kisah al Quran yang Mujmal (global), maka mereka menanyakan penjelasan atau tafsiran ayat tersebut dari Aslam (seorang ahli kitab). Karena di dalam kitab-kitab agama samawi baik Taurat maupun Injil, terdapat banyak kesamaan di dalam penyebutan beberapa kisah, walaupun berbeda dari segi pemaparan kisah-kisah tersebut.

Para Sahabat ra sangat berhati-hati dalam menerima riwayat yang bernuansa Israiliyyat, mereka tidak bertanya kepada ahli kitab kecuali untuk menjelaskan hal hal yang Mubham (samar) dan Mujmal yang belum dijelaskan oleh Rasulullah SAW. Dan mereka juga tidak menyibukkan diri dengan pertanyaan tentang perkara-perkara yang tidak perlu (non sense), karena hal tersebut percuma dan sia-sia. Pada masa tabi' in telah berkembang pesat pengambilan informasi dari ahli kitab, sehingga banyak cerita Israiliyyat di dalam Tafsir. Begitu pula zaman setelah tabi' in, mereka tasahhul dalam mengambil riwayat kisah dari ahli kitab sehingga didapati kisah-kisah yang tidak masuk akal dan dapat menghancurkan pemahaman terhadap nash-nash yang Sharih.

Dikatakan, mayoritas cerita Israiliyyat terdapat pada kisah-kisah para Rasul, mukjizat dan umatnya. Dan juga pada sejarah selain Rasul, seperti kisah Ashabul Kahfi, tentang kota-kota yang dihancurkan, tentang sihir di Babylon, juga tentang perkara-perkara gaib yang termasuk tanda-tanda hari kiamat. Banyak pula terdapat khurafat dan mitos-mitos dusta. Sehingga Ahmad bin Hanbal berkomentar bahwa 3 perkara yang tidak memiliki sumber: Tafsir, Al 
Malaahim, dan Al Maghaaziy.

Para ulama berbeda pendapat mengenai hukum meriwayatkan kisahkisah Israiliyat, dan perbedaan hukum disesuaikan dengan klasifikasi dari macam Israiliyat itu sendiri.

Dr. $\mathrm{M}$ al Dzahabi dalam al Israiliyat Tafsir wa al Hadits membagi Israiliyat dalam tiga macam:

1. Israiliyat berdasarkan kebenaran dan tidak

Menurut kebenaran dan tidaknya, Israiliyat terbagi menjadi dua macam, yaitu benar dan palsu.

a. Benar, seperti cerita Israiliyat yang datang membenarkan apa yang ada dalam al Quran mengenai sifat-sifat Muhammad SAW (al Khalidy: 44), Allah SWT berfirman:

"Hai Nabi sesungguhnya kami mengutusmu untuk jadi saksi, dan pembawa kabar gembira dan pemberi peringatan, dan untuk jadi penyeru kepada Agama Allah dengan izin-Nya dan untuk jadi cahaya yang menerangi" (QS al Ahzab: 45-46).

Sifat-sifat ini telah disebutkan dalam Taurat dan para penelaah Taurat telah menyatakan secara terus terang mengenai hal itu. Rasulullah SAW bersabda:

"Beritahukanlah padaku tentang sifat Nabi SAW dalam taurat. "Abdullah berkata, "baik, demi Allah,beliau bersifat dalam Taurat seperti sifatnya dalam al Quran, "wahai Muhammad sesungguhnya Kami mengutusmu sebagai saksi, pemberi kabar gembira dan pemberi peringatan serta tempat berlindung bagi kaum buta huruf, engkau adalah hamba-Ku dan rasul-Ku, namamu adalah al Mutawakkil bukan sebagai orang yang berperangai kasar, dan keras. Allah tidak akan mencabut nyawanya sehingga dengannya ia meluruskan agama yang bengkok dengan mengatakan" Tidak ada Tuhan selain Allah, dengannya ia membuka hati yang tertutup, telinga yang tuli dan mata hati yang buta" (HR.al Bukhari no. 4461dan 1981, Ahmad bin Hanbal, no. 6333, CD Kutub al Tis'ah).

b. Palsu, seperti legenda gunung "Qaf" yang mengitari langit dan bumi, sebagaimana yang didakwakan oleh para pembohong (al Khalidy: 45).

2. Israiliyat berdasarkan kesesuaian atau tidak kesesuaian dengan Islam

Menurut kategori kesesuaian dan ketidaksesuaian dengan Islam, Israiliyyat terbagi menjadi tiga macam, yaitu sebagai berikut:

a. Israiliyyat yang sesuai dengan Islam

Contoh untuk hal ini adalah hadits yang diriwayatkan oleh al Bukhari 
dari Abi Said al Khudzri ra. Rasulullah SAW bersabda:

"Nabi bersabda: bumi pada hari kiamat menjadi sepotong roti yang digenggam Allah dengan tangan-Nya, sebagaimana seorang diantara kamu menggenggam sepotong roti dalam safar, sebagai peersingggahan bagi penduduk surga". Lalu datanglah seorang Yahudi seraya berkata:" semoga Allah memberkatimu, wahai Abu Qasim, maukah kamu saya beritahukan tentang persinggahan penduduk asli surga? Nabi menjawab: "ya..." orang Yahudi itu berkata:" bumi menjadi sepotong roti sebagaimana yang dikatakan Nabi SAW."lalu, Nabi menoleh pada para sahabat kemudian tertawa sampai terlihat gigi gerahamnya". (HR. Bukhari no. 6039, dan Muslim no. 5000, CD kutub al Tis'ah).

b. Israiliyat yang berbeda dengan syariat Islam

Contoh dalam hal ini adalah apa yang dinisbatkan orang-orang Yahudi kepada Nabi Harun as dalam kitab Safrul Khuruj bahwa dialah yang membuat anak sapi jantan untuk bani Israel dan mengajak mereka untuk menyembahNya. Juga tentang apa yang mereka nisbatkan kepada Allah SWT dalam kitab Safrut Takwin bahwa ketika Allah SWT menciptakan langit dan bumi dalam enam hari, Ia merasa letih lalu istirahat pada hari ke tujuh, yakni hari sabtu (al Khalidy, tt: 45).

\section{c. Israiliyyat yang didiamkan oleh Syariat kita}

Contoh dalam hal ini adalah seperti diriwayatkan dari cerita Israiliyyat seputar rincian kisah sapi betina Bani Israel yang bermula dari membunuhnya seorang lelaki demi pamannya, kemudian tuntutannya terhadap orang lain atas kematian pamanya dengan penyembelihan sapi betina, penghidupan kembali orang yang terbunuh itu dengan sapi betina yang disembelih, dan pemberitahuan dari orang yang hidup kembali itu tentang orang yang membunuhnya (al Khalidy:46).

\section{Pembagian Israiliyat berdasarkan tema}

Menurut kategori topiknya, Israiliyat teerbagi menjadi tiga macam: a. Israiliyat berkaitan dengan akidah

Contoh dalam hal ini bisa kita baca Hadits yang diriwayatkan oleh Imam Bukhari dari Abdullah bin Mas'ud mengenai keadaan bumi ketika hari kiamat, di mana Nabi membenarkan perkatan pendeta tersebut dengan membacakan firman Allah:

"Dan mereka tidak mengagungkan Allah dengan pengagungan yang semestinya padahal bumi seluruhnya dalam genggaman-Nya pada hari kiamat 
dan langit digulung dengan tangan kanan-Nya. Maha Suci Tuhan dan Maha Tinggi Dia dari apa yang mereka persekutukan” (QS al Zumar: 67).

b. Israilliyat berdasarkan Hukum

Contoh dalam hal ini adalah apa yang diriwayatkan oleh al Bukhari dari Abdullah bin Amr mengenai hukuman orang yang berzina, di mana dalam Taurat pun disebutkan "hukum rajam bagi pezina".

"Bahwa orang Yahudi- datang kepada Nabi SAW. Dengan membawa seorang pria dan wanita dari kalangan mereka keduanya telah berzina. Nabi SAW bertanya kepada mereka, «bagaimana kalian memperlakukan seseorang diantara kalian yang telah berzina?» mereka mengatakan, «kami mencoreng wajah mereka dan memukul mereka. «lalu beliau bertanya lagi, «apakah kalian tidak menemukan dalam Taurat hukum rajam? «mereka menjawab, «kami tidak mendapatkan sesuatupun.. maka berkatalah Abdullah bin Salam, «kalian telah berdusta! Bawakan Taurat, lalu bacalah taurat itu jika kalian memang benar.» Lalu diantara mereka meletakkan telapak tangannya pada catatan Taurat menutupi ayat rajam. Maka orang tersebut membaca ayat yang berada di sebelum dan di sesudah ayat yang terletak di bawah telapak tangannya serta tidak membaca ayat rajam, lalu Abdullah mengangkat tangan orang itu dari (menutupi ayat rajam), seraya bertanya apa ini? Maka ketika mereka melihat itu mereka mengatakan «ia adalah ayat rajam». Nabi memerintahkan untuk merajam kedua orang pezina tersebut, mereka dirajam di dekat tempat jenazah disemayamkan di sisi masjid...," (HR. al Bukhari: 3363 dan Muslim Hudud: 3211).

c. Israiliyat yang berhubungan dengan nasihat, hikmah, kisah dan sejarah

Contoh dalam hal ini adalah apa yang diriwayatkan oleh riwayat Israiliyat tentang cerita pembuatan kapal Nabi Nuh as tentang kayu, panjang, dan lebarnya kapal, serta peristiwa-peristiwa yang terjadi pada Nabi Nuh as.

Setelah kita melihat macam dari Israiliyat dengan tiga kategori, maka penulis bisa mengambil kesimpulan:

1. Kita tidak bisa memastikan kebenaran apapun dari Israiliyat kecuali al Quran dan hadits memastikannya.

2. Riwayat Israiliyat yang benar menurut sumber kita maka statusnya menjadi wawasan pengetahuan kita.

3. Israiliyat yang menyalahi dan mengingkari syariat kita maka tidak boleh meriwayatkannya, kecuali hanya untuk menjelaskan kekeliruannya.

4. Riwayat yang palsu, kita tidak diperbolehkan untuk meriwayatkannya. 


\section{Tujuan kisah}

Kisah-kisah dalam al Quran tidak hanya sebagai pelengkap, tapi di dalamnya banyak tujuan yang ingin dicapai di antaranya:

1. Menetapkan dan juga membenarkan bahwasanya Muhammad SAW adalah rasul yang diutus oleh Allah, dengan membawa satu risalah seperti halnya nabi-nabi sebelumnya yaitu beribadah kepada Allah. (al Thanthawi, al Qishshah, 1996: 4) sesuai dengan firman-Nya:

Artinya: "Wahai kaumku sembahlah Allah, sekali-kali tak ada Tuhan bagimu selain-Nya. Sesungguhnya (kalau kamu tidak menyembah Allah), aku takut kamu akan ditimpa azab hari yang besar" (QS al A'raf: 59).

Artinya:"Hai kaumku, sembahlah Allah, sekali-kali tidak ada Tuhan bagimu selain-Nya. Maka mengapa kamu tidak bertakwa kepada-Nya?" (QS al A'raf: 65).

2. Bukti kebenaran bahwa al Quran adalah kitab yang diturunkan kepada Nabi Muhammad. Al Quran banyak mengisahkan kisah-kisah nabi terdahulu, yang Nabi Muhammad sendiri tidak pernah menyaksikannya (Thanthawi: 5).

Artinya: Kami ceritakan kisah mereka kepadamu (Muhammad) dengan sebenarnya. Sesungguhnya mereka itu adalah pemuda-pemuda yang beriman kepada Tuhan mereka dan Kami tambahkan kepada mereka petunjuk.

3. Meneguhkan hati Rasulullah SAW dan umatnya atas agama Allah SWT, memperkuat kepercayaan orang mukmin atas kebenaran (Ali al Majdub: 25).

"Dan semua kisah dari rasul-rasul Kami ceritakan kepadamu, ialah kisah-kisah yang dengannya Kami teguhkan hatimu; dan dalam surat ini telah datang kepadamu kebenaran serta pengajaran dan peringatan bagi orang-orang yang beriman" (QS Hud: 120).

4. Menjelaskan bahwa agama seluruhnya dari Allah, sejak masa Nabi Nuh sampai nabi Muhammad SAW dan bahwa orang mukmin seluruhnya adalah umat satu, sedangkan Allah SWT menjadi Tuhan mereka semua (Sayyid Quthb, 2004: 163). Dalam surat al Anbiyaa sesudah menyebutkan kisah nabi Musa, Harun, Ibrahim, Luth, Daud, Sulaiman, Ayyub, Ismail Idris, Zulkiflli, Zunnun, dan Zakaria, firman Allah SAW diakhiri dengan: "Sesungguhnya (agama tauhid) ini adalah agama kamu semua; agama yang satu dan Aku adalah Tuhanmu, maka sembahlah Aku" (QS al Anbiyaa: 92). 
5. Mengingatkan umat manusia akan bahaya Iblis yang suka menyesatkan manusia. Kisah ini juga menunjukkan permusuhan abadi antar Iblis dan manusia.

6. Menerangkan kekuasan Allah untuk menciptakan peristiwa-peristiwa luar biasa. Seperti kisah kejadian Adam as dan kisah lahirnya Isa as (Sayyid Quthb: 171).

7. Pendidikan (pengajaran). Yaitu, membentuk perasaan yang kuat dan jujur ke arah akidah Islamiyah dan prinsip-prisipnya, dan ke arah pengorbanan jiwa untuk mewujudkan kebenaran dan kebaikan.

8. Meringankan beban jiwa atau tekanan jiwa para Nabi dan orang-orang beriman. Hal ini disebabkan perkataan orang-orang musyrik dan perilaku serta sikap mereka yang suka mendustakan ajaran Islam.

9. Memberikan harapan dan sugesti, al Quran merealisasikannya dengan menumbuhkan semangat atau tekad yang kuat untuk membersihkan lingkungannya dari berbagai norma kesusilaan dan kemasyarakatan yang bertolak belakang dengan al Quran (Khalafullah: 332-335).

\section{Simpulan}

Kisah dalam al Quran memiliki pesona dan daya pikat tersendiri, tidak hanya pada alur kisah akan tetapi pada penempatan satu kisah dalam berbagai surat dalam al Quran sama sekali tidak ada pertentangan seperti yag dituduhkan para musyrikun. Dalam setiap kisah yang ada dalam al Quran ada banyak makna yang tersirat, sehingga banyak hikmah dan pelajaran yang bisa digali oleh umat Nabi Muhammad SAW. Dalam memahami kisah-kisah al Quran, terdapat manhaj Qurani yang harus dimiliki pengkaji kisah agar tidak terjerumus pada mitos-mitos maupun dongeng di antaranya: kisah adalah hal ghaib yang hanya Allah-lah yang tahu secara detail runtutan kisah-kisah itu, jadi kita tidak boleh merujuk pada sumber-sumber yang al Quran dan Hadits sendiri tidak menampilkannya, kita harus konfirmasi ulang setiap berita yang datang.

\section{Daftar Pustaka}

Abdurrahim, Muhammad. 1995. Mu'jizat wa Ajaib, Beirut: Dar al Fikr.

Ali, Atabik dkk. 1996. Kamus Kontemporer Arab-Indonesia. Yogyakarta: Yayasan Ali Maksum.

Al Khalidi, Shalah Abdul Fattah. 4523 H. Ma'a Qashash al Sabiqin fi al Quran. 
Damsyik: Dar al Qalam.

Al Khalidi, Shalah Abdul Fattah. 4523 H. al Qashash al Quran: 'Ardhu wa Qai' wa Tahlil Ahdats. Damsyik: Dar al Qalam.

Al Khatib, Abdul Karim. 1974. Qashash al Quran fi Manthuqihi wa Mafhumihi. al Qahirah: Maktabah al Madani.

Al Khatib, Abdul Karim. 1973. Min Qadhaya al Quran. al Araby: Dar al Fikr.

Al Thanthawi, Muhammad Sayyid. 1996. al Qishshah fi al Quran al Karim. al Qahirah: Dar Nahdhah Mishr.

Al Utsaimin, M. bin Shalih. Dasar-dasar Penafsiran. Diterjemahkan oleh Said Agil Munawwar dan Rifki Mukhtar. Semarang: Dina Utama.

Al Zuhaili, Wahbah. Tafsir al Munir fi al Aqidah wa al Syariah wa al Manhaj. Dar al Fikr: Beirut.

Al Majdub, Ahmad Ali. 1989. Ahli Kaafi fi al Taurah wa al Injil wa al Quran. al Qahirah: al Dar al Mishriyyah al Bananiyyah.

Al Qaththan, Mana Khalil. 1973. Mabahits Fi Ulum al Qura. Riyadh: ttp.

Arifin, Bey. 1998. Rangkaian Cerita dalam al Quran. Bandung: al Ma'arif.

Hanafi, Ahmad. 1984. Segi-segi Kesusasteraan pada Kisah-kisah al Quran. Jakarta: Pustaka al Husna.

Ibrahim, Muhammad Ismail. 1969. Mu'jam al Alfadz wa A'lam al Quraniyyat. Dar al Fikr al Arabi.

Khalafullah, Muhammad A. 2002. Al Quran bukan Kitab Sejarah: Seni Sastra dan Moralitas dalam al Quran. Diterjemahkan oleh Zuhairi Misrawi. Jakarta: Paramadina.

Munhanif, Ali. 2002. Hawa sebagai Symbol Ketergantungan: Perempuan dalam Kitab Tafsir. Jakarta: Gramedia Pustaka Utama.

Munawwir, Ahmad Warson. 1997. Kamus al Munawwir. Surabaya: Pustaka Progresif.

Quthb, Sayyid. 2004. Indahnya al Quran Berkisah. Jakarta: GIP. 
Setiawan, M. Nur Kholis. 2005. Al Quran Kitab Sastra Terbesar. el SAQ: Yogyakarta.

Shihab, M. Quraish. 2002. V. 5. Tafsir al Misbah: Pesan-Pesan dan Keserasian al Quran. Jakarta: Lentera Hati. 